\title{
Nevoid Basal Cell Carcinoma Syndrome (Gorlin Syndrome) in Children
}

\author{
S. Binsheikhan, S. Mittal and M. Al Abadie
}

\section{ABSTRACT}

Introduction: Gorlin syndrome or nevoid basal cell carcinoma syndrome (NBCCS) is a rare genetic disorder characterised by development of multiple basal cell carcinomas (BCC) at a young age.

Case report: A 7 year female child presented with MULTIPLE skin growths on the neck, face and upper chest for 3 years, with prominent forehead and mild non-scarring alopecia. She also had a history of medulloblastoma treated 3 years ago. There was no significant family history. Biopsy from one of the lesions showed basal cell carcinoma (BCC).

Discussion: Nevoid basal cell carcinoma syndrome (NBCCS) is an autosomal dominantly inherited disorder caused by mutations in the tumour suppressor patched 1 (PTCH-1) gene. Patients present with both cutaneous and extra-cutaneous manifestations. Multiple basal cell carcinomas (BCCs) are one of the most frequent cutaneous manifestations, occurring on both photo-exposed and non-exposed areas. The commonest extra-cutaneous tumours are medulloblastomas, which are often the first presentation of the disease. There are multiple but no established treatment modalities for the disease.

Keywords: Gorlin syndrome, medulloblastoma, nevoid basal cell carcinoma syndrome.

Submitted: May 22, 2021

Published: September 30, 2021

ISSN: $2593-8339$

DOI: 10.24018 /ejmed.2021.3.5.888

\section{S. Binsheikhan}

Department of Dermatology, NMC

Royal Hospital, Abu Dhabi, UAE.

(e-mail: dermasm@gmail.com)

S. Mittal *

Department of Dermatology, NMC

Royal Hospital, Abu Dhabi, UAE.

(e-mail: drsaurabh0811@gmail.com)

M. Al Abadie

Department of Dermatology, The Royal

Wolverhampton NHS Trust,

Wolverhampton, UK.

(e-mail: mohammed.abadie@nhs.net

*Corresponding Author

\section{INTRODUCTION}

Gorlin syndrome is a rare genetic disorder characterised by development of multiple basal cell carcinomas (BCC) at a young age. It is also known as nevoid basal cell carcinoma syndrome (NBCCS) and is caused by mutations in the tumour suppressor patched 1 (PTCH-1) gene. We present here a case of young girl with multiple basal cell carcinomas (BCCs) on the upper body and history of medulloblastoma.

\section{CASE REPORT}

A 7 years old female presented with complaints of multiple skin growths on the neck, face and upper chest for the past 3 years. The lesions were asymptomatic but had been growing rapidly. In addition, she also had a prominent forehead and some non-scarring hair loss. She has had a past history of medulloblastoma which was successfully treated with chemotherapy and radiotherapy, till about 3 years ago. She had been doing well all this time without any signs of recurrence of the neurological tumour. Also, the last radiological scan done for the patient was not suggestive of any recurrence. There was no family history of any cutaneous or non-cutaneous malignancies.

On examination, she had multiple discrete skin coloured to yellowish dirty looking, fleshy, greasy papules and papulo- nodules on the face, neck and upper chest, along with a few pinkish soft nodules (Fig. 1).

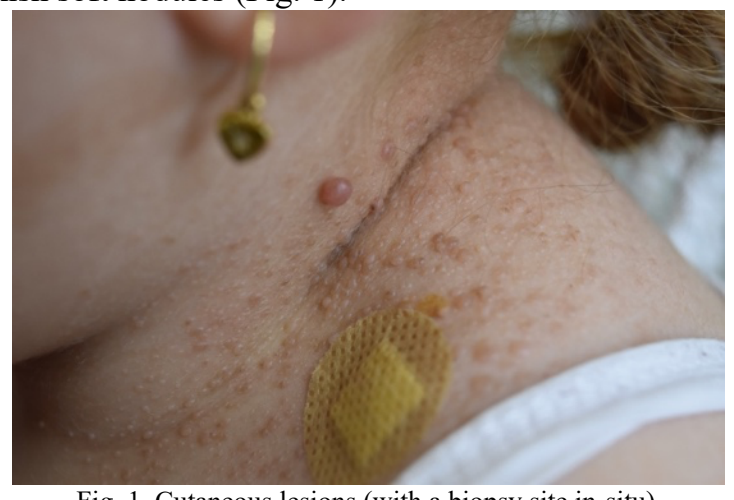

Fig. 1. Cutaneous lesions (with a biopsy site in-situ).

There were two kinds of lesions identified on dermoscopy (Dermlite DL4, 10x):

1) pigmented lesions with multiple pigmented dots and globules, in the majority, suggesting seborrheic keratosis.

2) pinkish lesions with arborising and hair pin vessels, in the minority, suggesting basal cell carcinoma (BCC) (Fig. 2).

Excision biopsy was done from the most representative lesion (identified by dermoscopy as basal cell carcinoma (BCC). The sample was sent for histopathology as well as immuno- histochemistry.

The microscopic examination showed intradermal wellcircumscribed irregular shaped islands of atypical basal cells in superficial dermis, with hyperchromatic nuclei, and scant 
cytoplasm. There was peripheral nuclear palisading, focally forming lacelike pattern within myxoid stroma, and nests of cells retracting from the stroma. There was no perineural or lymphovascular invasion (Fig. 3).

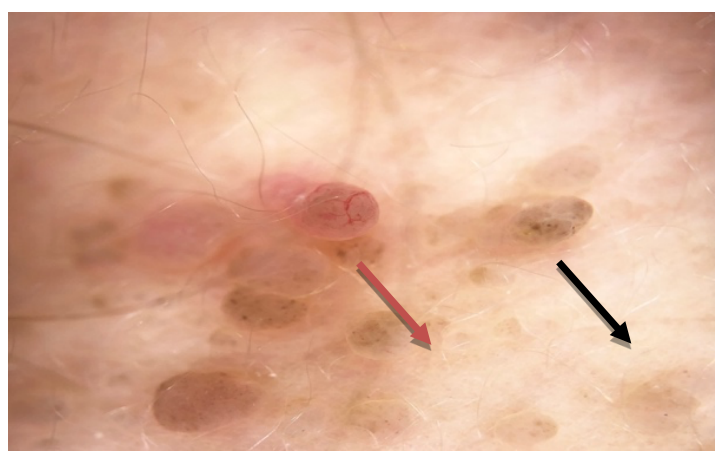

Fig. 2. Black arrow-dots and globules signifying seborrheic keratosis like lesion; Red arrow-arborising vessels suggesting BCC like lesion (Dermlite DL4, 10x).

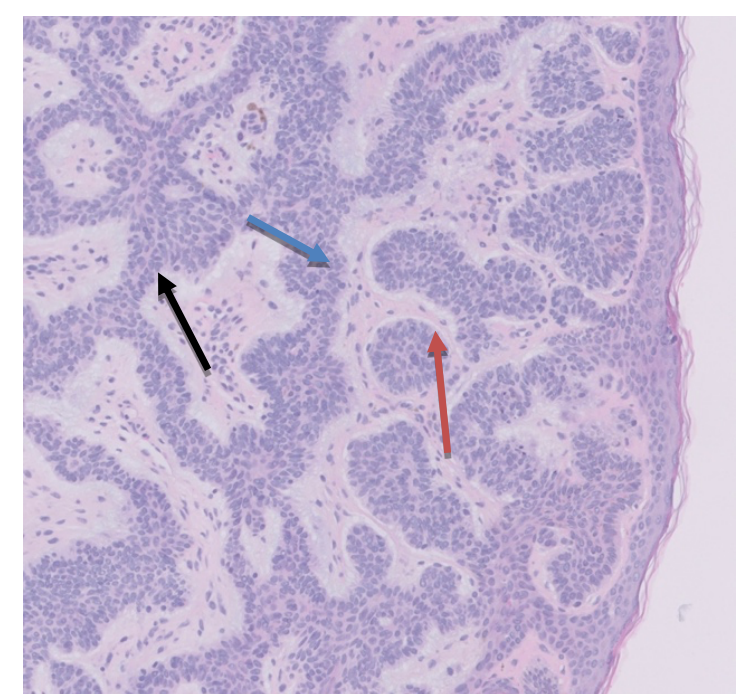

Fig. 3. Nests of cells (black arrow) with peripheral palisading (blue arrow) with stromal clefting (red arrow).

Immunostaining revealed Bcl-2 positivity (Fig. 4) in addition to Ki67 with negative CK20 and CD10 which favoured basal cell carcinoma (BCC) over trichoblastoma.

The parents were called for a follow up, after being informed about the biopsy report, to discuss further treatment options, but they were lost to follow up.

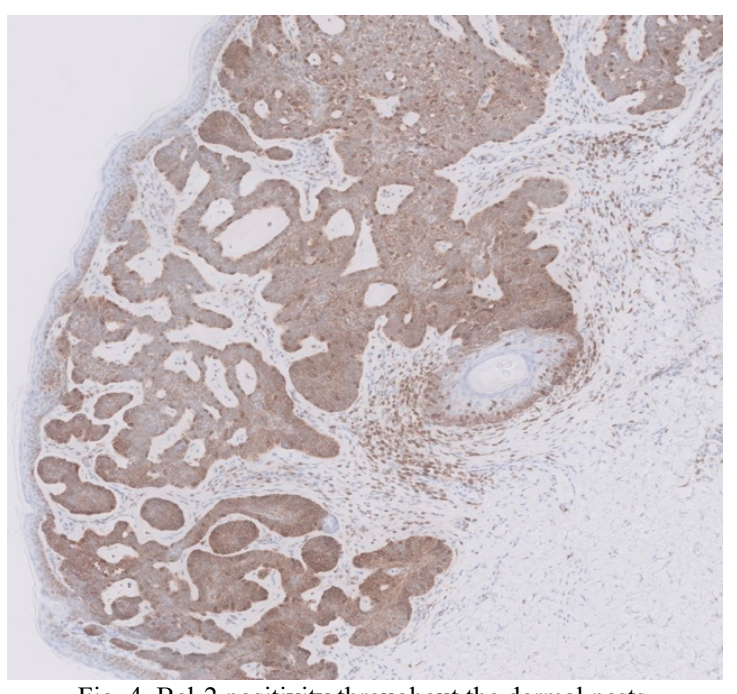

Fig. 4. Bcl-2 positivity throughout the dermal nests.

\section{DiscussiON}

Gorlin or nevoid basal cell carcinoma syndrome (NBCCS) is an autosomal dominantly inherited disorder with variable penetrance. It was described as a syndrome by Dr. Gorlin and Dr. Goltz in 1960 in a family with basal cell carcinomas (BCCs), jaw and bifid ribs [1]. It is caused by mutations in the tumour suppressor gene PTCH-1, predisposing the affected individuals to tumour formation, particularly multiple basal cell carcinomas (BCCs) [1], [2]. PTCH-1 forms part of the sonic hedgehog (SHH) signaling pathway.

Gorlin syndrome presents with both cutaneous and extracutaneous manifestations. Multiple basal cell carcinomas (BCCs) is one of the most frequent cutaneous manifestations, occurring on both photo-exposed and nonexposed areas, usually on the skin of the head and neck and upper-third of the trunk, [3] as was seen in our patient. In recent times, dermoscopy is a convenient and fast tool to make a diagnosis of basal cell carcinoma (BCC) and/or to assist in choosing an appropriate lesion to be biopsied, to avoid multiple procedures, as the patients are usually young. Other reported manifestations reported are palmar/plantar pits, multiple melanocytic naevi and epidermoid cysts, [4] none of which were seen in our patient. Since the age of development of cutaneous lesions is variable, all the features may not be present simultaneously and can develop at a later age.

There is a plethora of extracutaneous manifestations reported in Gorlin syndrome including but not limited to the manifestations in the jaw, central nervous system (CNS), facial abnormalities, bony abnormalities, limb, ocular and auditory abnormalities, along with non-cutaneous tumours. Commonest of these presentations is odontogenic cysts and calcification of falx cerebri [4]. The commonest extracutaneous tumours are medulloblastoma, which are often the first presentation of the disease, [5] as was present in our patient. Although genetic testing is considered the gold standard for diagnosis, genetic testing is not recommended as routine and is only to be done if the diagnosis is in doubt or an affected family member is there.

Several diagnostic criteria have been proposed over time for the diagnosis of nevoid basal cell carcinoma syndrome (NBCCS) but the sensitivity and specificity of these have not been evaluated. The diagnostic criteria proposed by the International consensus (albeit not formal) are the presence of:

1) one major criterion and molecular confirmation [1];

2) two major criteria;

3 ) one major and two minor criteria [2].

As can be seen, our patient satisfied two major criteria and was thus confirmed to be a case of nevoid basal cell carcinoma syndrome (NBCCS). After confirmation of the diagnosis, based on the clinical features, past history and biopsy, a further follow-up and treatment was planned for the patient, however the patient did not turn up owing to the COVID-19 pandemic and was subsequently lost to follow-up despite multiple attempts. Follow-up and investigations of the disorder are varied and depend on the age, manifestations and the available resources, but it's recommended to minimise the exposure to ionising radiations. Radiological examinations are recommended to diagnose various abnormalities as well as a regular neurological examination is recommended [5]. 
TABLE I: DIAGNOSTIC CRITERIA FOR NEVOID BCC SYNDROME

\begin{tabular}{|c|c|}
\hline Relevance & Criteria \\
\hline \multirow{7}{*}{ Major } & $\begin{array}{l}\text { BCC prior to } 20 \text { years old or excessive numbers of BCCs } \\
\text { out of proportion to prior sun exposure and skin type } \\
\text { Od }\end{array}$ \\
\hline & age \\
\hline & Palmar or plantar pitting \\
\hline & Lamellar calcification of the falx cerebri \\
\hline & Medulloblastoma, typically desmoplastic \\
\hline & $1^{\text {st }}$ degree relative with NBCCS \\
\hline & Rib anomalies \\
\hline \multirow{6}{*}{ Minor } & $\begin{array}{l}\text { Other specific skeletal malformations and radiologic } \\
\text { changes (i.e., vertebral anomalies, kyphoscoliosis, short } \\
\text { fourth metacarpals, postaxial polydactyly) }\end{array}$ \\
\hline & Macrocephaly \\
\hline & Cleft lip/palate \\
\hline & Ovarian/cardiac fibroma \\
\hline & Lymphomesenteric cysts \\
\hline & $\begin{array}{l}\text { Ocular abnormalities (i.e. strabismus, hypertelorism, } \\
\text { congenital cataracts, glaucoma, coloboma) }\end{array}$ \\
\hline
\end{tabular}

There are multiple treatment modalities owing to the multitude of manifestations present. The treatment for basal cell carcinomas (BCCs) includes approaches such as excisions, MOHS micrographic surgery and physical destruction with electrocoagulation and cryotherapy. Other treatments such as topical imiquimod, photodynamic therapy (PDT) and 5-fluorouracil (5-FU) have also been used. FDA approved drug Vismodegib [6] can be used for local or metastatic basal cell carcinomas (BCCs). It acts on the SHH pathway, specifically inhibiting the SMO (Smoothened signal transducer) receptor, and was approved by the FDA for metastatic or locally advanced basal cell carcinomas (BCCs) that cannot be treated by surgery or radiotherapy [7].

Our case represents one of the rare dermatological syndromes with classical presentation. Nevoid basal cell carcinoma syndrome (NBCCS) presented at a young age and the presence of basal cell carcinoma (BCC) at a young age should prompt suspicion. Children with medulloblastoma should be followed up for development of any skin manifestations and should be thoroughly evaluated, if that happens. Also, it highlights the importance of using dermoscopy as an important bedside tool to identify the most representative biopsy site to minimize the number of biopsies needed to make a confirmed diagnosis. should prompt suspicion. Children with medulloblastoma should be followed up for development of any skin manifestations and should be thoroughly evaluated, if that happens. Also, it highlights the importance of using dermoscopy as an important bedside tool to identify the most representative biopsy site to minimize the number of biopsies needed to make a confirmed diagnosis.

\section{REFERENCES}

[1] F. Bree, M. R. Shah, "Consensus statement from the first international colloquium on basal cell nevus syndrome (BCNS)", Am. J. Med. Genet., vol. 155, pp.2091-2097, 2011.

[2] H. Hahn, C. Wicking, P. G. Zaphiropoulous, M. R. Gailani, S. Shanley, A. Chidambaram...A. E. Bale "Mutations of the human homolog of Drosophila patched in the nevoid basal cell carcinoma syndrome", Cell, vol. 72, no. 6, pp. 841-851, Jun 1996.

[3] R. Gorlin, "Nevoid basal-cell carcinoma syndrome" Medicine (Baltimore),vol. 66, pp. 98-113, 1987.

[4] Palacios-Álvarez, R. González-Sarmiento, E. Fernández-López, "Síndrome de Gorlin", Actas Dermosifiliogr, vol. 109, pp. 207-217, 2018.

[5] S. F. Amlashi, L. Riffaud, G. Brassier, X. Morandi, "Nevoid basal cell carcinoma syndrome: relation with desmoplastic medulloblastoma in infancy. A population-based study and review of the literature", Cancer, vol. 98, pp. 618-624, 2003.

[6] Sekulic, M. R. Migden, K. Lewis, J. D. Hainsworth, J. A. Solomon, S. Yoo ... A. Hauschild "Pivotal ERIVANCE basal cell carcinoma (BCC) study: 12 month update of efficacy and safety of vismodegib in advanced BCC", J. Am. Acad. Dermatol., vol. 72, pp. 1021-1026, 2015.

[7] S. Y. Wong, A. A. Dlugosz, "Basal cell carcinoma. Hedgehog signaling, and targeted therapeutics: the long and winding road", $J$. Invest. Dermatol., vol. 134, pp. E18-22, 2014. 